\title{
Safety of Smart Cities
}

Dana Prochazkova, Jan Prochazka

Czech Technical University in Prague, Faculty of Transportation Sciences, Praha, Czech Republic

prochazkova@fd.cvut.cz

prochazka@fd.cvut.cz

\begin{abstract}
Present work is based on the concept of integral safety management of system of systems and it gives the proposal of set of measures into the simultaneously modern concept of communities called "smart cities". The target is to ensure the safe smart city, i.e. the human community that will ensure the security and the development of their citizens under the conditions of normal, abnormal and critical. This demand is important because the mentioned diversity of life conditions is the result of both, the dynamic development of world and the human errors at control of behaviour of human society in the community.
\end{abstract}

\section{Indexing terms/Keywords}

Disaster; risks; safe system of systems; integral safety; smart city; security of citizens.

\section{Academic Discipline And Sub-Disciplines}

Community management at emergency situations.

\section{SUBJECT CLASSIFICATION}

Management

\section{TYPE (METHOD/APPROACH)}

\section{Critical assessment}

\section{INTRODUCTION}

Humans everywhere from the historical times want to live in a sufficient safe living space with a certain development potential, i.e. it means that they consciously need to manage the human society behaviour so its result might be safe communities, safe areas, safe sites etc. (EU 2004, Prochazkova 2011). Since the human needs, interests and wishes are filled by material and immaterial properties and goods that have utility value, so humans consciously need to build their residences (communities) as the safe human systems. It means that humans need to take care of:

\section{public assets,}

linkages and flows among assets,

linkages and flows of system with the surroundings,

and especially to try so they might not to threaten the system surroundings, namely even at its critical conditions (Prochazkova 2015).

Tools of humans for ensuring the above mentioned target are: management; education; legislation, standards and norms; plans; the material, technical and financial reserves; and trained personal for the fulfilment of tasks at the level technical, organizational, functional; tactical and strategic (Prochazkova 2011,2015). The process of creating the safe community (human system) is based on the strategic development plan for safety of given community (object, city, territory, and State).

The process in question started in developed countries in the 1990s of last century(Prochazkova 2011). From the professional point of view the strategic plan is de facto the safety management plan of community that ensures the security and development of humans in community today and in the future (Prochazkova 2011a,b). Its concept is based on the system understanding the reality and it respects the public interest. The presented work focuses on the concept of communities build up as the smart cities and it creates tools for ensuring their safety.

\section{REQUIREMENTS ON HUMAN SETTLEMENTS}

On the basis of assessment carried out in work (EU 2014) it has been shown that present urban planning:

has tendency to neglect the complex interrelations in regional development, i.e. it is mainly focused on the bare rank, does not consider the long-term development strategies,

strengthens the existing stereotypes,

uses generalize approach because many financiers ask for clear results which can easily be communicated with public,

has many rankings aimed at finding the "best" or "most attractive" city in general terms.

Consecutively it tries to cover all fields of local attractiveness totally ignoring the fact that different activities need different conditions. It is quite obvious, however, that a city that offers a high quality of life does not necessarily have to be the ideal location for all industrial branches. On the basis of current knowledge about the recent urban development in Europe and the sustainability of human settlements, which is summed up in the work (Prochazkova, Prochazka 2014), in the cities with a large concentration of population and activities there are problems with protection of human health and human security. It is connected with three factors, i.e.:

- $\quad$ military actions

- natural disasters 
social conflicts, civil disorder and crime.

Poverty and poor health are often the part of inanition and dehumanization development spiral, affecting often some key parts of cities throughout the Europe. Therefore, in conflict areas it should be supported and promoted the concept of noncombat urban zones as a part of international agreements. Measures on protection against the disasters should be at all levels the components of plans for the development and management of cities. In planning it should be supported the measures against the causes of social unrest and crime in the cities. Planning should help to restore a sense of civic relations and social welfare, increasing the level of personal security in cities (Prochazkova 2011a, Prochazkova, and Prochazka 2014).

Sustainability intuitively means the capability to have the processes of changes in landscape, territory or another reference entity under a specific control (command, or even more up to date term the change management). In that context, the sustainability is closely linked with stability as a measure of changes impacting the productivity, safety, security, protection, economic growth and social acceptability. In general, the principles of sustainability include integrity, sufficiency and opportunity, fairness, efficiency and prudence (Prochazkova, Prochazka 2014).

The city is the territory in which humans live. It represents the complex open system of systems, in which there are processes that ensure the quality of humans' life. Each of their greater distortion means a threat to the existence and development of humans. Safe human system, for which the EU politicians often use the designation of "Safe space" (EU 2004 ) is defined as a system in which the safety is at an acceptable level and in which it takes care on the human security and the public good.

The human system is thus the minimum amount of space for life of humans and whole human society, i.e. it includes the elements that make up: humans; part of environment necessary for the life of humans; part of the planet Earth for life of humans; property; technology; infrastructure; and linkages and flows among these elements. Protected assets of human system (assets) are the selected elements, linkages and flows in the human system, which are necessary for its security, and sustainable development. They are primarily protected and they include the lives, health and security of humans, property, the environment, the public good, technology and infrastructure (Prochazkova 2011a).

On the basis of current knowledge, summarized in the works (Prochazkova 2011a,b, 2015, Prochazkova, and Prochazka 2014), the management of human system (which represents a territory with a population that colonizes it) oriented on security and the sustainable development of humans is focused on:

- $\quad$ reveal of disasters, which are natural, social, and technological disasters, as well as the failures of various linkages and flows in the human system,

- $\quad$ precede of disasters, if it can be possible, e.g. at natural disasters it is not possible,

- removal of causes of origin of heavy (severe, serious) impacts of disasters, or at least reduction of their occurrence frequency,

- $\quad$ mitigating the unacceptable disasters' impacts by preventive measures, preparedness, optimal copping with impacts of disasters and with critical situations that are induced by disasters (i.e. actually by reduction of duration of emergency situations to an acceptable degree),

- $\quad$ ensuring the territory recovery after disasters and starting up the further development.

Therefore, the objective of strategic plan of development is the survival of community (i.e. inhabitants and basic public assets), because the disasters should not in any way impair the long-term functions of community. Therefore, today it is promoted the development variant (CDEM 2002, DA 2003, EMA 1996, FEMA 2005, Gibson et al. 2001, Gustin 2002,Pettterson 1999, Prochazkova, Prochazka 2014, US 2003), which is based on five axioms:

1. It is demanded in order to it might be constantly available functions of production, distribution and consumption, involving the local participation in the production, distribution and consumption of products and services that are the part of everyday life. Every major disaster can seriously disrupt the functions in question, while the daily consumption of daily goods, even during and after the disaster does not change.

2. Every major disaster changes priorities, because the public institutions focus on the care of victims and business activity can be suspended.

3. Every major disaster means that all the traditional social and cultural activities will not take place.

4. In the case of every major disaster there is temporarily "suppressed" some laws such as traffic offence and vice versa there are highlighted laws on security and public order, regulation of the movement.

5. The primary function which is characteristic for the community, is the mutual assistance, by which it is solved the situation of citizens and families who have got into difficulties.

Development on the one hand, requires the institutional and structural transformation of community; on the other hand, it may be slowed by the impacts of disaster acting on the basic functions of community. Therefore, the plans for the sustainable development of community need to be based on risk management in time course. On its basis it needs to be built the community protection system based on prevention, preparedness, response and recovery with regard to the potential disasters (Prochazkova 2011a,b, 2015) and regarding to it the precautionary principle needs to be applied (Prochazkova 2011a), since in the available data there are random and knowledge uncertainties, and it is necessary to ensure the protection also against highly unacceptable impacts of disasters that are not expected on the basis of our present knowledge.

\section{SMART CITIES AND INTEGRAL SAFETY}

The smart city (intelligent city) is the term that is at present used for denotation of communities, i.e. the residential complexes from the viewpoint of quality, performance and interactivity of urban services (EU 2014). It includes such residential complexes which require at living to reduce the costs and resource consumption and to improve the contacts 
between citizens and government (public administration). Into the sectors that have been using the smart city technology there are included government services, transport and traffic management, energy, health care, water and waste handling. The smart cities applications are developed with the goal to improve the management of urban flows and to facilitate responses to challenges in real time. A community "smart city" is for that reason prepared to respond to challenges better than conmmunity with a simple 'transactional' relationship with its citizens.

Every human system, i.e. territorial unit inhabited by humans, has its own characteristics and it is from time to time damaging by the disasters of different size (Prochazkova 2011a). Damages, losses, harms and injury caused by disaster depend on both, the disaster size, and the amount of assets and their vulnerabilities against the given disaster, i.e. it is necessary to consider the size of risks (Prochazkova 2011a,b) and according to them, and according to the possibilities of given territorial unit to control the community safety; i.e.:

the protection of public assets,

the mobilization and coordination of utilization of community resources (energy, labour force, production capacity, food and agriculture, raw materials, telecommunications, etc.),

the coordination of activities such as a system of warning, the system of rescue and medical services, which reduce the impacts of disasters and ensure the continuity of activities of public administration and the adherence of laws, and also create the conditions for starting the development

(Prochazkova 2011a,b, 2015).

On the basis of current knowledge (Prochazkova 2011a, 2015) each quality control needs to respect the necessity to make a decision with a view to: preventing the emergency situations and locate emergency situations; ensure the healthy development of human population; and implement environmental programmes in the socio-economic sphere.

The basic functions of States and cities since their origin it is to ensure the protection and development of human society, which is not possible without ensuring a safe space in which the human society lives. The safety is understood as a set of human measures and actions for ensuring the safe human system, i.e. for ensuring the security and sustainable development of protected assets of human system.

Because the human system is variable as well as a tool for ensuring its security and sustainable development needs to be a variable, i.e. the human needs to manage it. According to the principles of modern human society management the tasks belong to all participants (Prochazkova 2011a, 2015).

On the basis of above given facts, it is necessary for each territorial unit to know the characteristics of given territory, at least in the scope of territorial planning documentation and data on:

the structure and the nature of population,

larger disasters, which can be expected in a given territory,

local vulnerabilities to disasters,

available resources, forces and means of community.

By objective way it is necessary to evaluate the risks in the system concept (Prochazkova 2011b) and to process the safety management plan.

\section{DATA ON SMART CITIES AND THEIR JUDGEMENT FROM THE VIEWPOINT OF HUMAN SAFETY AND METHODS FOR SMART CITIES SAFETY BUILD UP}

When we take the Internet site google.com and overview of current publications on smart cities, we find many hundreds to thousands of projects on strategic development of cities around the world, applying the smart cities concept; the cities are scattered across the globe (e.g. Amsterdam, Barcelona, London, Washington, Stockholm, Santa Cruz, Rio de Janeiro, Tokyo, Auckland, Seoul, Prague etc.).

The analysis of more than 50 projects, which are described on the cited Web server, and of data from publications (Batty et al. 2012, DA 2003, EU 2015, Greenfield 2013, Kwon Hyung Lee 2013, Moir, Moonen, Clark 2014, Shepard 2011, Townsend 2013), shows that the smart city is a modern urban project, which sees the development of medium-sized cities in the interface of quality infrastructures energy, transport, telecommunications and green and in the education, culture and business with high value added.

In the studied projects it does not assume the existence of disasters, although it is not site in the world which has not been affected by any disaster as it is shown by database (EM-DAT), which is analysed in detail in (Prochazkova 2014); and every major disaster will cause losses on human lives and health and damages, harms and injury to public assets, i.e. it disrupts life in community. Figure 1 shows the impacts of extreme disasters on the community and progressive cascade of failure life sustaining infrastructures (Prochazkova 2011a,b).

Because for ensuring the human wishes it is the primary task of each community to ensure the human security in time, as it is shown in the previous chapters and the EU material (EU 2015), it can be said in accordance with the work (Greenfield 2013) that the realized projects of smart cities usually do not solve all aspects important for the human safety. However, because they have a large number of positive features, the smart cities concept should be supplemented with tools for emergency and crisis management (Prochazkova 2011a).

The first solved problem in this paper consists in the determination of items that need to be considered in the smart city concept so its safety might be on the acceptable level. At solution it was used the following procedure:

creation the normative model of safe smart city, understand as the system of systems according to principles given in (EU 2013, Prochazkova 2011a,b, 2015),

identification of critical items by the judgement of harmony between the normative model of safe smart city and the frequent present model of smart city (EU 2015),

identification of critical items by the judgement of harmony between the frequent present model of smart cities (EU 2014) and expected future demands given in the foresight of future development of smart cities (Moir, Moonen, Clark 2014), 
identification of critical items by the judgement of harmony between the frequent present model of smart cities (EU 2015) and identified needs of cities specified in work (UN 2014).

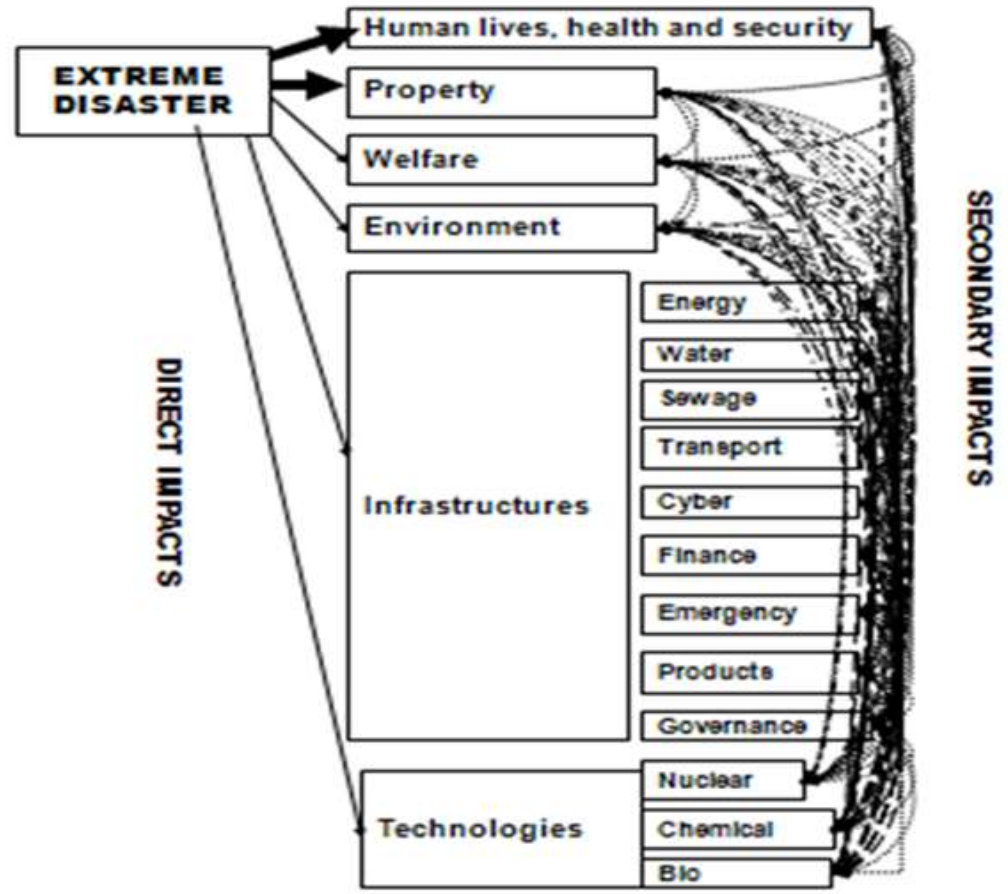

Fig 1: The impacts of beyond design (extreme, severe, heavy) disaster on the human system assets. There are given direct impacts on the protected public assets and the relevant secondary impacts caused by links and flows in the human system, and also the cases for which there are safeguards in the developed countries - bold arrows (Prochazkova 2011a)

The other solved problem in this paper consists in creation of procedure for ensuring the safe smart city today and in next times. At solution it was used the method of analogy to the models that have been processed for safe communities and safe facilities on the integral safety concept (OECD 2003, Prochazkova 2011a,b, 2015) and that have been proven in practice.

\section{ITEMS THAT NEED TO BE CONSIDERED IN SMART CITIES CONCEPT}

The recent applications of smart cities concept in the face of efficiency have been using the innovative ICT technologies and rely on the fact that all interconnected systems will still work well. It is the fact that none of given technologies is absolute, as it is shown by the failures of control systems in the technological facilities, e.g.: on 21.1.2016 the trains were neither accepted nor send off from the Main railway station in Praha even several hours due to the fact that according to the report of Rail governance in the mass media the control computer did not work; failure of device of high tech equipment PZB90 that is installed on the German railways was one of causes of collision of fast trains near town Bad Aibling in Bavaria on 9. 2.2016, at which 10 people were killed, five people were severely injured and almost 200 people injured; and many blackouts and many other outages of services described in work (CVUT, Prochazkova 2015). Therefore, the management of each smart city needs to consider:

natural disasters and technological accidents (called external) of another systems,

the terrorist attacks, criminal acts or war

technological accidents (called internal) of critical elements, links and flows in the own system. It is necessary to consider the material defects, aging, lack of maintenance of facilities and devices, etc.

errors or failure of the control system,

human errors, namely the causes of organizing accidents as bad decisions of managers and bad ways of control.

Above all, it is necessary to consider the failures of smart technologies and to have prepared procedures to overcome these failures and to ensure the recovery in a way that does not raise the critical impacts on humans and other important public assets, the consequence of which there are great losses of human lives and harms on human health, or the inability to stabilize the situation and to perform the recovery.

Using the continuous monitoring it is necessary to follow if:

the safety level (effectiveness and efficiency of human measures and activities) in a time is rising or going down,

at defined time intervals it is achieved the planned level of safety (efficiency and effectiveness of the measures and activities),

and applied measures actually lead to the increase of safety level (efficiency and effectiveness of human measures and activities).

Therefore, in each project of smart city it is necessary:

to determine what and why it is necessary to protect,

to provide for a minimum level of protection, 
to assess the current level of protection,

in the case of finding that the protection is insufficient to propose further measures for the protection,

to provide the means for protection,

to apply the measures for the protection,

periodically to check the security level in community,

to maintain protection at the appropriate level,

to revise the measures depending on developments.

For all activities it is necessary to divide competences and responsibilities among the participants. The technical and organizational aspects, which need to be addressed, are listed in (Prochazkova 2013, 2015).

\section{MODEL FOR SMART CITIES SAFETY MANAGEMENT IN TIME}

With regard to: data and knowledge summarized in (PRochazkova 2011 a,b, 2015); the concepts promoted by the OECD (OECD 2003); methods described in work (Prochazkova 2015); and the assumption that each community "smart cities“ is an open system of ssystems (i.e. the sources of risks are the internal and external disasters and human factor (Prochazkova 2011a,b)), it is created a model for safety management having the six processes, i.e.: concepts and governance; administrative procedures; technical matters; external cooperation; emergency preparedness; and the documentation and the investigation of accidents (Figure 2).

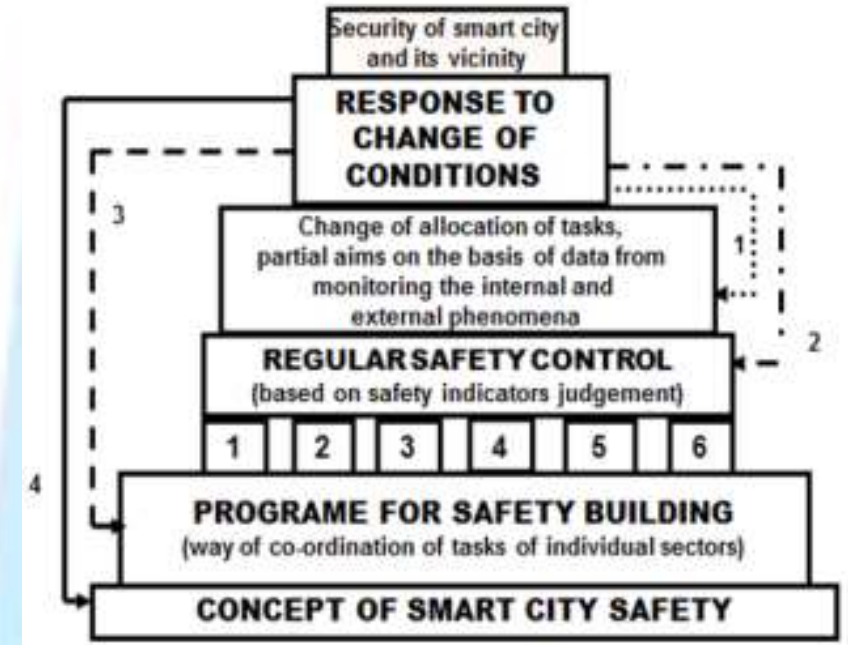

Fig 2: Model of management of smart cities safety; seven blocks of processes important for smart cities safety; dotted line — feedback 1; broken line — feedback 2; dashed line — feedback 3; full line - feedback 4

The processes are further divided into sub processes:

1. The first process consists of sub processes for: the overall concept for ensuring the safety; achieving the intermediate objectives of safety; leadership / management of safety; the safety management system; management of personnel staff including the sections for: human resources management, training and education, internal communication / awareness and working environment; review and evaluation of implementation of fulfilment of objectives in the safety.

2. The second process consists of sub processes for: identification of hazards from potential disasters and assessments of risks connected with these hazards; documentation of procedures (including the work permits); management of changes; ensuring the safety in conjunction with contractors; and supervision under the safety of products.

3. The third process includes the sub processes for: research and development; design and mountings; procedures for ensuring the inherent safety; formulation of technical standards; storage of hazardous substances; and maintenance of integrity of community and maintenance of its equipment and buildings.

4. The fourth process includes the sub processes for: cooperation of all stakeholders with the administrative authorities; cooperation with the public and other stakeholders (including the academic institutions); and cooperation with other important public and private facilities.

5. The fifth process includes the sub processes for: planning of internal (on-site) preparedness on cope with emergency situations of all kinds; ensuring the items that facilitate the planning of external (off-site) preparedness (for which it is responsible the public administration) for case if facility threatens its vicinity; and the coordination of activities of all departmental (resorts) facilities at ensuring the departmental emergency preparedness and the response, namely to critical situations (crisis management).

6. The sixth process has sub processes for: processing of reports on disasters, accidents, incidents, near misses and other learned experiences; investigation of damages, losses and harms and their causes; and the response and follow-up activities after disasters (including the lessons learned and information sharing).

Since any real community is in the dynamically varying world, its situation has been changing in dependence on the realization of potential risks, and therefore, each community needs according to (Prochazkova 2015) to monitor the risks and to respond to changes in the conditions by the way that it has in its governance the procedures for the management of community at normal and abnormal conditions, and even at critical conditions (caused by beyond design disasters), at which it uses the measures indicated on Figure 2 by back-links (the feedbacks are implemented gradually according to the severity of conditions, i.e. the feedback 4 is used in the greatest severity). 
Programme for building the safety is according to (Prochazkova 2011b) the safety management plan, which contains a coherent set of plans:

security plan, i.e. the procedure, by which it is created a secure smart city,

plan of response of smart city to emergency and especially to critical situations,

recovery plan of smart city after the critical situations, by which it will be in the first stabilized the situation in smart city and after then it will start up further development.

For safety management of smart cities at a time, it needs also to create the safety culture, which is respected by both, the smart city top management and as well as its residents. Important there are tools as: the continuous monitoring; the allocation of responsibilities; and the determination of competences (EU 2013, Gustin 2002, Prochazkova 2011a). For a skilled mastery of emergency and critical situations it is necessary to provide the backup sources of power and resources, and a trained staff who know the procedures for overcome of unacceptable impacts of disasters (Gustin 2002, Prochazkova 2011a, 2014).

\section{CONCLUSIONS}

Model for safety management of smart cities compiled on the basis of present knowledge is the process model in which they are represented the both:

the individual important elements of process of safety management based on qualified work with integral risk,

the feedbacks by which it is possible to correct the cases in which demands of safety are not fulfilled owing to the dynamical development in smart cities and in their vicinities.

For application in practice the model for smart city safety management is supplemented by mechanism for ensuring the capability to be effective at abnormal and critical conditions; i.e. the operational competent plans, backups material, technical, financial and personal, and also specific types of management (Prochazkova 2011a).

The above given results show that for ensuring the smart city safety during its life cycle including the human survival at critical conditions, it is necessary:

to use quality way of work with risks which is directed to system of systems safety,

at construction of objects (buildings), facilities and infrastructures to apply "All-Hazards-Approach" and "Defence-InDepth principle" (Prochazkova 2015),

to have the safety management programme based on smart city safety management plan containing: the model of management of smart city safety shown in Figure 2; the processes for safety management of individual components and their interfaces; and set of plans for solution of: smart city security; and response to emergency and crisis situation in smart city (especially those for case if smart technologies fail).

\section{ACKNOWLEDGEMENTS}

Authors thanks to Czech Technical University in Prague for support (grant SGS2015-17).

\section{REFERENCES}

I. Batty, M. et al. 2012. Smart cities of the future. European Journal of Physics Special Topics 214,481-518.

II. CDEM 2002. Working together: Lifelines Utilities and Emergency Management. Ministry of Civil Defense and Emergency Management (CDEM), www.civildefense.govt.nz

III. CVUT. Archive of technological accidents and failures. Praha: CVUT.

IV. DA 2003.Disaster Advisors Inc. - Business continuity planning. http://www.disasteradvisors.com/ disasterplanning.htm

V. EM-DAT. The OFDA/CRED international disaster database - www.emdat.net - Université catholique de Louvain Brussels - Belgium. www.emdat.be

VI. EMA, 1996. Australian emergency manual disaster recovery. Sydney: Emergency Management Australia, 166p.

VII. EU 2004. Safe community. Brussels: EU 2004. www.eu.org

VIII. EU 2013. FOCUS project. Brussels: EU. www.focusproject. eu

IX. EU 2014. Smart cities Ranking of European medium-sized cities. www.smart-cities.eu

X. EU 2015. ISO/IEC, JTC 1 Smart cities". Geneve: International Organization for Standardization. www.iso.org

XI. FEMA 2005. Promoting Critical Infrastructure Protection by Emergency Managers and First Responders. Nation-wide. www.usfa.fema.gov.

XII. Gibson, B. R. et al. 2001.Specification of sustainability-based environmental assessment decision criteria and implications for determining "significance" in environmental assessment. Report EN 105-67/2001E. Ottawa: Canadian Environmental Assessment Agency. ISBN 0-662-31068-3, www.ceea-acee .gc.ca

XIII. Greenfield, A.A. 2013. Against smart city. London: Verso, 153p.

XIV. Gustin, J. F. 2002. Disaster \& recovery planning: a guide for facility managers. Lilburn: The Fairmont Press, Inc. ISBN 0-88173-323-7 (FP), 0-13-009289-4 (PH), 304p.

XV. Kwon Hyung Lee 2013. Building a new smart city in Asia: Songdo international city in Incheon S. Korea. Incheon Development Institute.

XVI. Moir, E., Moonen, T., Clark, C. 2014. What are future cities - origins, meaning and uses. Foresight future of cities Catapult: Project and Future Cities London: Catapult, 98p.

XVII. OECD 2003. Guidance on safety performance indicators. guidance for industry, public authorities and communities for developing SPI programmes related to chemical accidents. Paris: OECD, 202p.

XVIII. Petterson, J. A. 1999. Review of the literature and programs on local recovery from disaster. Colorado: Natural Hazards Research and Applications Information Center, Institute of Behavioral Science, University of Colorado 1999. http://www.colorado.edu/ hazards/wp/wp102/wp102 org.html

XIX. Prochazkova, D. 2011a. Strategic management of safety in territory and organisation. ISBN: 978-80-01-04844-3. 
XX. Prochazkova, D. 2011b. Risk analysis and management. ISBN: 978-80-01-04841-2. Praha: CVUT, 405p.

XXI. Prochazkova, D. 2013. Identification and management of risks of system of systems. International Journal of Computer an Information Technology, ISSN: 2279-0764, 2, No 2, 232-239. http://ijcit.com/current.php

XXII. Prochazkova, D. 2014. Risks connected with disasters and engineering procedures for their defeat. ISBN 978-80-0105479-6. Praha: CVUT, 234p.

XXIII. Prochazkova, D. 2015. Safety of complex technological facilities. ISBN: 978-3-659-74632-1. Saarbruecken: Lambert Academic Publishing, 244p.

XXIV. Prochazkova, D., Prochazka, J. 2014. integral safety ensures optimum development of environment. ISBN 978-80-0105480-2. Praha: CVUT, 224p.

XXV. Shepard, M. 2011. Sentient city: ubiquitous computing, architecture, and the future of urban space. ISBN 9780262515863. New York City: Architectural League of New York.

XXVI. Townsend, A. 2013. Smart cities: big data, civic hackers, and the quest for a new utopia. W. W. Norton \& Company. ISBN 0393082873.

XXVII. UN 2014. UN Habitat 2014 - The city we need. www.unhabitat.org/downloads/docs/The\%20City\%20 We\%20 Need.pdf

XXVIII. US 2003. The national strategy for the physical protection of critical infrastructures and key assets. 2003; http://www.whitehouse.gov/pcipb/physical_strategy.pdf

\section{Author' biography with Photo}

Assoc. Prof., Dr. Dana Prochazkova, PhD., D.Sc. studied the Faculty of Mathematics and Physics, Charles University at Praha, worked in research in Czechoslovak Academy of Sciences, Ministry of the State Control of the Czech Republic, State Office for Nuclear Safety, Ministry of Interior - Fire and Rescue Service of the Czech Republic, and in Czech Technical University in Praha. The whole work life she has been lectured in the Charles University (Praha), the Komensky University (Bratislava), the Czech Technical University (Praha), the Technical University - Faculty of Safety Engineering (Ostrava), the College on regional and legal studies (Ceske Budejovice) and in the Jan Amos Komensky University (Praha). The objectives of professional works have been seismicity, seismic engineering, seismotectonic relations, responses of constructions and their equipment to the earthquakes, evaluation of soil conditions to the construction behaviour, nuclear engineering, disasters, crisis management, emergency management, risk and safety management, engineering, legal and technical measures etc. She published 20 professional books and more than 500 professional papers in the English, in the Czech, in the Russian, in German and in the Chinese.

RNDr. Jan Prochazka, Ph.D. studied the Charles University in Praha, Faculty of Mathematics and Physics. He has been working in the Czech Technical University, Faculty of Transportation Sciences in department for security technologies and safe infrastructures. The objectives of professional works have been quantum physics, optoelectronic, material properties, hazardous materials, protection against hazardous substances, engineering problems, emergency management, crisis management and risk management. He published 32 professional papers and participating on 15 professional reports containing the real problems solution.

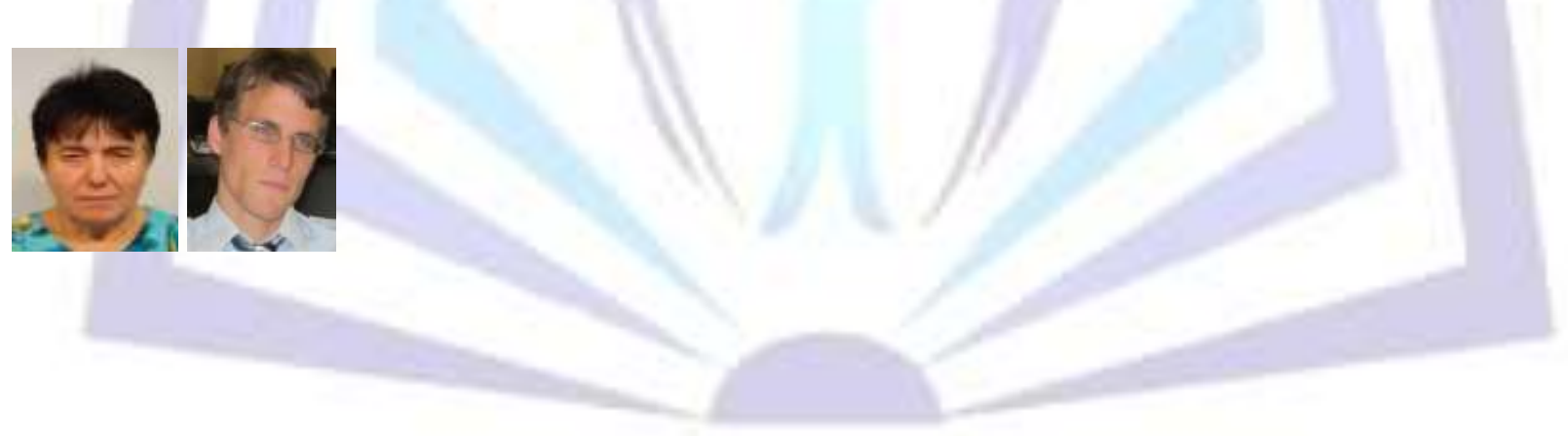

